\title{
Recursos educacionais multimidiáticos para o estímulo à leitura na educação infantil
}

\section{Educational resources multimediatics for reading in early childhood education}

1 Doutora em Letras. Professora Associada. Universidade Federal de Santa Catarina. Pesquisadora na área de leitura, mídias e ensino. Organizadora do livro "Multimídia Digital na Escola".

E-mail: elenice.andersen@ufsc.br
Este artigo analisa recursos educacionais para a leitura na educação infantil disponibilizados em uma plataforma governamental seguindo a tendência de olhar a primeira infância como a base do desenvolvimento humano (MARCO LEGAL PARA A PRIMEIRA INFÂNCIA, 2013). Defende, a partir de abordagens cognitivas do desenvolvimento, que o uso de recursos educacionais multimidiáticos para essa fase requer atenção especial, sobretudo quanto à adequação dessas ferramentas às necessidades cognitivas e linguísticas na infância. Defende, igualmente, que o uso de ferramentas mais próximas à realidade das crianças pode funcionar como incentivo à leitura, promover o multiletramento (ROJO e MOURA, 2012), e, dessa forma, agir como fator de proteção para dificuldades de leitura presentes na educação básica. A análise qualitativa baseou-se em três categorias: (i) objetivos do recurso; (ii) adequação do recurso à fase de desenvolvimento linguístico e cognitivo da criança; e (iii) adequação do recurso à pedagogia do multiletramento. Conclui que há uma carência de variedade de recursos educacionais disponibilizados, com predomínio de uma mídia em detrimento de outras, e um empobrecimento na qualidade desses recursos. Com isso, outras fontes para o trabalho com a linguagem na educação infantil são sugeridas.

PALAVRAS-CHAVE: Recursos educacionais; Leitura; Desenvolvimento Infantil; Multiletramento.

ABSTRACT: This article discusses the production of educational resources for early childhood education with a focus on reading, available on a government platform for free use, following the current trend of looking at early childhood as the basis of human development (MARCO LEGAL PARA A PRIMEIRA INFÂNCIA, 2013). It argues that the use of multimediatic educational resources for this phase requires special attention, especially with regard to the suitability of these tools to cognitive and linguistic needs of the child, according to the cognitive development approaches. It concludes that there is a lack of variety of educational resources provided by the government for the examined area, with a predominance of media over others and an impoverishment in the quality of resources. Thus, other sources to work with language in early childhood education are suggested.

KEYwoRDS: Educational Resources; Reading; Child Development; Multiliteracy. 


\section{Introdução}

Marco Legal para a Primeira Infância pôs em evidência a criança de até seis anos como parte da sociedade. Projeto de Lei, de número 6.988/2013, aprovado no Senado e recentemente sancionado pela Presidente da República, prevê a participação da criança na formulação de políticas públicas e de ações específicas para cada idade e realizadas por profissionais capacitados. De acordo com o documento, evidências científicas em educação, neurociência, psicologia e, inclusive, em economia têm comprovado que é no período da Primeira Infância que se lançam as bases de todo desenvolvimento posterior do ser humano e da sociedade. Assim, o período é considerado estratégico para a promoção do desenvolvimento humano, social e econômico. Quando aprovado, o Marco Legal da Primeira Infância pretende dar ao Brasil o título de primeiro País da América Latina a valorizar a primeira fase da vida (MARCO LEGAL DA PRIMEIRA INFÂNCIA, 2013).

Nesse contexto de pensar a primeira fase como alicerce para o desenvolvimento humano e social, chamamos a atenção para a necessidade do incentivo à leitura, já na primeira infância, como parte fundamental de promoção do desenvolvimento humano. Esse pensamento se justifica por diferentes razões, entre as quais, destacamos três. A primeira refere-se ao fato de que a leitura é reconhecidamente parte do domínio da língua para a participação social efetiva, para o exercício da cidadania e um direito inalienável de todos, como bem salientam os Parâmetros Curriculares Nacionais (Língua Portuguesa - 1a a $4^{\underline{a}}$ séries). A segunda, diz respeito à baixa eficiência do Brasil em garantir esse direito. Como sabemos, o país apresenta baixos índices em programas de avaliação da leitura ${ }^{1}$. Nas fases

\footnotetext{
Destacam-se, entre os programas de avaliação, o SAEB (O Sistema de Avaliação da Educação Básica é uma avaliação governamental composta dois processos: a Avaliação Nacional da Educação Básica for International Student Assessment é um Programa Internacional de Avaliação de Estudantes,
}

escolares iniciais, avaliações, como a Provinha Brasil, ${ }^{2}$ demonstram que as dificuldades em leitura já se apresentam desde muito cedo, e o desempenho geral é inferior às expectativas para a fase do desenvolvimento avaliada. Esses resultados evidenciam, em nossa leitura, a necessidade de discussões sobre mecanismos de proteção à criança antes de o problema estar instaurado. Finalmente, a terceira refere-se ao advento da cultura multiletrada, que tem influenciado, inclusive, os programas de avaliação em leitura, nos quais são frequentes questões envolvendo, por exemplo, a leitura de imagens.

Diferentes explicações têm sido apontadas para as dificuldades em leitura, entre as quais, os fatores psicossociais, tais como questões de ordem socioeconômica. Nesse quesito, menos mencionados, porém, são os resultados de pesquisas recentes que indicam que a exposição à leitura na primeira infância, entre outros, pode funcionar como fator de proteção para o desenvolvimento e para um melhor desempenho em leitura (DUURSMA et al., 2008; HANEY; HILL, 2004).

Tendo-se em vista pesquisas dessa natureza, um problema que se impõe é o do acesso das crianças provenientes de camadas populares a recursos de qualidade semelhante aos disponibilizados para as crianças de nível socioeconômico mais elevado. Nesse sentido, é a educação o espaço privilegiado para proporcionar a democratização do acesso aos recursos e é do Governo a responsabilidade de fomentar esse acesso.

"uma iniciativa de avaliação comparada, aplicada a estudantes na faixa dos 15 anos, idade em que se pressupõe o término da escolaridade básica obrigatória na maioria dos países". "O programa é Em cada país participante há uma coordenação nacional. No Brasil, o Pisa é coordenado pelo Instituto Nacional de Estudos e Pesquisas Educacionais Anísio Teixeira".

2 Provinha Brasil é "Provinha Brasil é uma avaliação diagnóstica que visa investigar o desenvolvimento Provinha Brasil é "Provinha Brasil é uma avaliação diagnóstica que visa investigar o desenvolvimento das habilidades relativas à alfabetização e ao letramento em Lingua Portuguesa e Matemática, desenvolvidas pelas crianças matriculadas no 2 o ano do ensino fundamental das escolas públicas passaram por, pelo menos, um ano escolar dedicado ao processo de alfabetização". 
Considerando o Portal do Professor ${ }^{3}$ como o espaço governamental para promoção e fomento de recursos e estratégias pedagógicas para a educação pública de qualidade, na qual se inclui a educação infantil, e argumentando pela atenção especial que deve ser dada, já na primeira infância, ao acesso a múltiplas formas de leitura, como proteção de dificuldades de leitura nos anos subsequentes, a presente pesquisa investiga e analisa os recursos educacionais voltados às práticas de leitura para a educação infantil no Portal do Professor. A análise quantitativa baseou-se no levantamento dos recursos mais frequentes na plataforma. A análise qualitativa baseou-se em três categorias: (i) objetivos do recurso, conforme a ficha técnica disponibilizada no Portal; (ii) adequação do recurso à fase de desenvolvimento linguístico e cognitivo da criança; e (iii) adequação do recurso ao potencial de incentivo à promoção de uma pedagogia do multiletramento. Para fundamentar as análises, fatores envolvendo a linguagem e leitura, em uma perspectiva cognitiva do desenvolvimento, foram revisados, conforme veremos na próxima seção.

\section{0 desenvolvimento da linguagem e da leitura na criança e os multiletramentos}

O desenvolvimento infantil passa por fases ou estágios mais ou menos dinâmicos. No que se refere ao desenvolvimento da linguagem, influências internas e externas podem influenciar esse desenvolvimento.

Entre as influências internas, o crescimento cerebral durante os primeiros anos da infância está intimamente relacionado ao desenvolvimento

\footnotetext{
De acordo com a página oficial, o Portal, lançado em 2008 em parceria com o Ministério da Ciência e Tecnologia "tem como objetivo apoiar os processos de formaça dos professores brasileiros e enriquecer a sua prática pedáógica. Este é um espaço público e pode ser acessado por todos os interiquas". Disponivica pestos abr. 2016.
}

da linguagem (MARTORELL, 2014). O tronco cerebral e a ponte são as primeiras a se desenvolver e controlam o choro de um neonato. $O$ balbucio pode surgir com a maturação do córtex motor, que controla os movimentos da face e da laringe. A percepção fonética do cérebro vincula-se aos sistemas motores já aos seis meses. E, ainda, o desenvolvimento da linguagem afeta ativamente as redes cerebrais, ajudando a criança a reconhecer os sons da língua. Finalmente, regiões corticais associadas à linguagem continuam se desenvolvendo nos anos pré-escolares tardios ou até a idade adulta (ibid.).

Para Martorell (2014), entre as influências externas, está o fato de que a linguagem é um ato social, de modo que pais e cuidadores desempenham um papel importante em cada fase do desenvolvimento. Existem evidências de que a fala a que a criança está exposta (input) é fator importante para a aquisição oral. Com alguns dias de vida, a criança tem uma reação positiva aos sons da fala, que lhe são confortadores e gratificantes (SCARPA, 2001). No decorrer das interações, a criança passa por períodos de desenvolvimento que podem ser observados, com ressalvas, aproximadamente desta forma:

As crianças começam com balbucio, primeiro com vogais (cerca de 3 a 4 meses, em média), depois com combinações de vogais e consoantes de complexidade crescente (geralmente entre 6 e 12 meses). As primeiras palavras emergem entre 10 e 12 meses, em média, embora a compreensão de palavras possa começar algumas semanas antes. Depois disso, as crianças passam várias semanas ou meses produzindo enunciados de uma palavra. No começo, a taxa de crescimento de seu vocabulário é reduzida, mas há um súbito acréscimo nela mais ou menos entre 16 e 20 meses. As primeiras combinações de palavras geralmente aparecem entre 18 e 20 meses e, no começo, tendem a ser telegráficas. Lá pelos 24 a 30 meses, há outra espécie de explosão vocabular e aos 3 ou 3 anos e meio, a maioria das crianças normais dominou as estruturas sintáticas e morfológicas de suas línguas maternas (SCARPA 2001).

Diferentemente da aquisição e desenvolvimento da linguagem oral, o aprendizado da leitura não ocorre de forma tão espontânea, apenas através 
da interação com o adulto. As crianças necessitam de ensino explícito para aprenderem a ler.

A leitura é uma atividade psicolinguística complexa composta por múltiplos processos interdependentes, e aspectos perceptivos, linguagem, inteligência, memória de trabalho e de longo prazo estão envolvidos na capacidade de ler (SALLES; CORSO, 2009). Além do reconhecimento da palavra, a leitura supõe a compreensão do texto lido, processo cognitivo de alto nível, que envolve, entre outros, a capacidade de realizar inferências, habilidades linguísticas gerais, habilidades de memória e conhecimento de mundo (ibid.). A linguagem escrita não dispõe de um aparato neuropsicológico preestabelecido. Ela precisa ser ensinada para o estabelecimento de circuitos cerebrais que a sustentem, o que se faz por meio do exercício (COSENZA; GUERRA, 2011).

Coelho (2000), ancorada em evidências da psicologia experimental, propõe estágios de desenvolvimento do leitor e apresenta sugestões para a estimulação da leitura em cada um desses estágios. Segundo a autora, esses estágios não dependem apenas da faixa etária, mas principalmente da interrelação entre sua idade cronológica, nível de amadurecimento biopsíquicoafetivo-intelectual, e nível de conhecimento do mecanismo da leitura. Entre os estágios propostos pela autora, os dois primeiros são os que interessam aos propósitos deste trabalho:

1. O Pré-leitor: Essa categoria inicial envolve duas fases:

a) Primeira infância (dos 15/17 meses aos 3 anos): é o momento em que a criança inicia o reconhecimento da realidade pelos contatos afetivos e pelo tato, começando a conquista da própria linguagem e passando a nomear as coisas. É uma fase em que o mundo natural e o mundo cultural começam a se relacionar na percepção do espaço global em que vive. Para estimular esse impulso natural, a criança deve ter acesso a gravuras de animais, bichos de pelúcia, chocalhos musicais etc. e cabe ao adulto o importante papel de manipular e nomear os brinquedos ou desenhos, inventando situações que os relacionem afetivamente com a criança.

b) Segunda Infância (a partir dos 2/3 Anos): fase em que se aprofunda a descoberta do mundo concreto e do mundo da linguagem por meio de atividades lúdicas. Em casa ou na escolinha, a presença do adulto é fundamental para orientar a brincadeira com o livro. Os livros adequados a essa fase devem ter predomínio absoluto da imagem (gravuras, ilustrações, desenhos etc.) sem textos ou com textos pequenos, que podem ser lidos ou dramatizados pelo adulto.

2. O leitor iniciante (a partir dos 6/7 anos): é a fase da aprendizagem da leitura, na qual a criança já reconhece os signos do alfabeto e a formação das sílabas simples e complexas. Ainda se faz necessária a presença do adulto, como "agente estimulador". Os livros, para essa fase, devem apresentar o predomínio da imagem sobre o texto; a narrativa deve desenvolver uma situação simples, linear com princípio, meio e fim; os personagens reais (humanos) ou simbólicos (bichos, plantas etc.) devem ter traços de caráter ou comportamento bem nítidos; o texto deve ser estruturado com palavras de sílabas simples, frases curtas; e os argumentos devem estimular a imaginação, a inteligência, a afetividade, as emoções, o pensar, o querer, o sentir. Ainda: as histórias que atraem as crianças são as bem-humoradas em que a astúcia do fraco vence a prepotência do forte, em que a inteligência vence o mal.

Da proposta da autora, é importante ressaltarmos que essas fases não são rígidas, nem estanques. É possível, por exemplo, que o desenvolvimento cogni- 
tivo do leitor iniciante possa se dar antes dos sete anos, a depender do acesso e convívio com recursos de leitura e o estímulo, em casa ou na escolinha.

De fato, Andrade et al. (2005) encontraram uma associação positiva e estatisticamente significante entre a qualidade da estimulação no ambiente doméstico e o desempenho cognitivo infantil geral. Os pesquisadores verificaram que a qualidade do estímulo doméstico é importante para o desenvolvimento cognitivo infantil. Além disso, destacam a relevância das condições materiais e da dinâmica familiar para esse desenvolvimento. Segundo os autores, os achados apontam a pertinência de ações de intervenção que favoreçam a qualidade do ambiente para o desenvolvimento cognitivo (ANDRADE, et al., 2005).

No que se refere à atividade leitora, existem evidências de que a exposição à leitura no ambiente doméstico, além da oferta de recursos físicos, brinquedos e jogos adequados para a idade da criança são importantes para o aprendizado e o desempenho escolar (DUURSMA et al., 2008; HANEY; HILL, 2004). Além disso, a pobreza limita as oportunidades de desenvolvimento (CECONELLO; KOLLER, 2000).

A falta de acesso a recursos educacionais de qualidade em escolas públicas, especialmente no período em que se formam as bases do desenvolvimento, como na educação infantil, pode contribuir para a desvantagem de aprendizagem de crianças menos favorecidas economicamente. A desvantagem torna-se ainda mais evidente, quando nos referimos a recursos tecnológicos, que costumam ser mais caros que os livros.

Além da desvantagem de aprendizagem, segundo Belloni e Gomes (2008), no que tange ao desenvolvimento infantil,

[...] a interação entre pares e com adultos, em situações favoráveis e inovadoras de aprendizagem e com uso pedagógico apropriado das Tecnologias de Informação e Comunicação, pode levar as crianças a desenvolverem comportamentos colaborativos e autônomos de aprendizagem, benéficos para seu desenvolvimento intelectual e sócio-afetivo (2008, p. 717).
A hipótese das autoras é a de que ambientes de aprendizagem computacionais tendem a ser eficazes para esta aprendizagem, pois possibilitam a mediação entre o sujeito e o objeto do conhecimento a ser construído (ibid.).

Quanto à leitura, isso se relaciona à cultura multiletrada, que vive a multiplicidade cultural das populações e a multiplicidade semiótica de constituição dos textos por meio dos quais ela se informa e se comunica (ROJO; MOURA, 2012). Para Belloni e Gomes (2008), os "novos modos de aprender" já vêm se desenvolvendo, desde que as crianças começaram a aceder à televisão e aos videogames e se amplificaram e complexificaram com o acesso e uso lúdico do computador e da internet, à revelia da escola e, de modo geral, ignorados por professores e especialistas.

Nessa perspectiva, fica evidente que o exame da qualidade dos recursos educacionais multimidiáticos disponibilizados para o desenvolvimento da criança na educação infantil torna-se essencial para proteger a criança de dificuldades com a leitura, em uma cultura multiletrada.

\section{Levantamento e análise dos dados no Portal do Professor}

Para o levantamento dos dados, realizamos uma consulta sistemática ao Portal do Professor (http://portaldoprofessor.mec.gov.br/sobre.html), no espaço multimídia. O Portal é uma plataforma governamental, lançada em 2008, em parceria com o Ministério da Ciência e Tecnologia, que tem por objetivo apoiar os processos de formação dos professores brasileiros e enriquecer a sua prática pedagógica. É um espaço público, acessado livremente, e a principal ferramenta do governo para disponibilização de recursos educacionais.

Para a consulta dos recursos educacionais, os critérios de seleção empregados foram os seguintes: educação infantil (como tipo de pesquisa), linguagem oral e escrita (como o componente curricular), práticas de leitura, 
práticas de escrita e falar e escutar (como tema) e português (como idioma). Até a data de 05/04/2016, foram encontrados 13898 recursos educacionais, dos quais 821 são voltados para a educação infantil, 269 apresentam como componente curricular "linguagem oral e escrita", e 138 dizem respeito ao ensino do idioma Português. Dos 138 recursos encontrados, 08 foram excluídos, por serem voltados para o ensino de línguas estrangeiras e 37 por serem voltados à formação do professor para a educação infantil, e não recursos para uso pedagógico. Dos recursos encontrados, portanto, 93 foram selecionados para análise. Observamos, ainda, os campos "coleções" e "sites temáticos", a partir dos mesmos critérios de seleção.

A análise quantitativa dos recursos disponíveis baseou-se no levantamento dos recursos mais frequentes. A análise qualitativa baseou-se em três categorias, quais sejam: (i) objetivos do recurso, conforme a ficha técnica disponibilizada no Portal; (ii) adequação do recurso à fase de desenvolvimento linguístico e cognitivo da criança; e (iii) adequação do recurso ao potencial de incentivo à promoção de uma pedagogia do multiletramento.

Quanto ao tipo, os recursos foram divididos conforme a classificação apresentada no Portal do Professor: animação/simulação; áudio, imagem, hipertexto, software educacional e vídeo. Os resultados encontrados, a partir dos critérios de seleção supracitados, foram:

Tabela 1 - Frequência dos recursos educacionais

\begin{tabular}{lc}
\hline \multicolumn{1}{c}{ Tipo de recurso } & Percentual (\%) \\
Animação/simulação & 2 \\
Áudio & 93 \\
Imagem & 0 \\
Hipertexto & 0 \\
Software educacional & 0 \\
Vídeo & $5 \%$ \\
\hline
\end{tabular}

Fonte: <http://portaldoprofessormec.gov.br/recursos>. Acesso em: abr. 2016.
Pela Tabela 1, podemos observar que há um predomínio quase absoluto (93\%) do áudio como recurso educacional para o trabalho com a linguagem na educação infantil, havendo apenas um pequeno percentual de recursos que envolvem mais de uma mídia, quais sejam, a animação/simulação e o vídeo (7\%). Recursos do tipo hipertexto e software educacional, que proporcionam o uso simultâneo de várias mídias não figuram entre os recursos para o trabalho com a linguagem na educação infantil.

No que se refere aos objetivos propostos para o uso dos recursos, foram encontrados 11 objetivos comuns aos diferentes recursos:

Tabela 2 - Tipos de recursos educacionais em relação aos objetivos

\begin{tabular}{|c|c|}
\hline Tipo de recurso & Objetivos \\
\hline Áudio & $\begin{array}{l}\text { - Despertar nas crianças o interesse em ouvir histórias narradas } \\
\text { e, a partir delas, instigar sua criatividade para a compreensão e } \\
\text { elaboração de narrativas. } \\
\text { - Despertar nas crianças o interesse em ouvir histórias narradas e, a } \\
\text { partir delas instigar a imaginação para suas próprias construções. } \\
\text { - Despertar nas crianças o interesse em ouvir histórias narradas e, a } \\
\text { partir delas instigar a criatividade de imaginação para a construção } \\
\text { das mesmas. } \\
\text { - Despertar nas crianças o interesse em ouvir histórias narradas } \\
\text { e, a partir delas instigar de imaginação para a construção das } \\
\text { mesmas. } \\
\text { - Despertar nas crianças o interesse em ouvir poesias narradas e, a } \\
\text { partir delas, instigar a criatividade e a imaginação para a construção } \\
\text { das mesmas. }\end{array}$ \\
\hline Vídeo & $\begin{array}{l}\text { - Trazer de uma forma lúdica a conscientização acerca da poluição } \\
\text { das marés. A mídia atua como colaboradora no processo de } \\
\text { desenvolvimento da expressividade, coordenação motora e } \\
\text { equilíbrio da criança. } \\
\text { - Explicar o significado e o uso dos ditos populares. } \\
\text { - Apresentar o mundo literário que envolve as cantigas populares } \\
\text { para as crianças, através do áudio e de imagens. }\end{array}$ \\
\hline Animação/simulação & $\begin{array}{l}\text { - Exercitar a leitura e interpretação de texto } \\
\text { - Exercitar a interpretação da leitura de imagens }\end{array}$ \\
\hline
\end{tabular}

Fonte: <http://portaldoprofessor.mec.gov.br/recursos>. Acesso em: abr. 2016. 
É importante destacar que a descrição do objetivo é idêntica para vários recursos, na apresentação da ficha técnica. Por essa razão, apesar do número elevado de áudio, encontramos apenas 05 objetivos nas fichas dessas mídias. Além disso, devemos destacar que os 05 objetivos identificados apresentam similaridades: propõem despertar o interesse em ouvir histórias ou poesias, a fim de estimular a criatividade e/ou a imaginação para a compreensão e/ou produção de narrativas. Esses objetivos se coadunam à proposta de estimular o interesse da criança pela leitura desde cedo e o gosto por histórias. Contudo, a ênfase quase absoluta no áudio, privilegia o desenvolvimento da percepção acústica, a compreensão leitora oral e o desenvolvimento da oralidade, além do pensamento imaginativo, que são importantes, mas não abre espaço para muitas das necessidades básicas da fase do desenvolvimento examinada. Além disso, são recursos nos quais a tecnologia não oferece vantagem. Pelo contrário, contar histórias para as crianças pode ser feito por um adulto, o que oferece a vantagem de uma maior interação com outro ser humano e estimulação da afetividade.

Conforme Coelho (2000), para estimular o impulso natural pela leitura das crianças nessa fase do desenvolvimento, faz-se necessário, principalmente, que a criança tenha acesso a imagens e atividades lúdicas. As imagens são proporcionadas principalmente pelos recursos em vídeo, e as atividades são proporcionadas pelos softwares educacionais. Os softwares educacionais possuem, como vantagem adicional, a possibilidade de interação do adulto com a criança ou, ainda, entre as próprias crianças. Lamentavelmente, são poucos os recursos dessa natureza oferecidos pelo Portal. A disponibilidade massiva de recursos em áudio não favorece, ainda, um preparo para a pedagogia do multiletramento.

Quanto às coleções de recursos, foram encontradas apenas 02 coleções: "Histórias Narradas para a Educação Infantil" e "Regras de Convivência: a
Influência das Práticas de Escrita na Educação Infantil". No Portal, a primeira é descrita como uma coleção que possui recursos pedagógicos que poderão incentivar a criança a interessar-se por histórias narradas, bem como por atividades de contação de histórias feitas por adultos e por elas próprias. Afirma, ainda, que os recursos selecionados procuram, através de histórias infantis narradas, ressaltar a criatividade e a imaginação nos diferentes modos que as crianças usam para se expressar.

A segunda coleção, "Regras de Convivência", faz interface com o trabalho com valores. Na ficha técnica, o Portal informa que a proposta busca incitar nas crianças ações que fortaleçam valores como paz, honestidade, respeito, solidariedade e amizade, entendendo que as manifestações escritas exercem papel preponderante, para que experiências de vida de cada criança sejam valorizadas. Os recursos selecionados procuram, por meio de histórias narradas, ressaltar a relevância das diferenças na construção de amizades e do respeito para com o outro.

Os recursos em ambas as coleções são do tipo “áudio", não disponibilizando outras mídias para atingir esses objetivos. Dessa forma, as coleções também privilegiam o desenvolvimento da percepção acústica e a compreensão leitora oral, em detrimento das demais necessidades da criança, além de não favorecer uma pedagogia para o multiletramento.

Quanto aos sites temáticos, o Portal não apresenta filtros para o tipo de pesquisa, de modo que não é possível identificar quais sites seriam indicados para a educação infantil, como foco em linguagem. Dessa forma, a partir de uma análise qualitativa da temática de cada site, foi possível identificar 02 sites para uso na área investigada, o "Literatura Infantil" e o "Brincadeira de Crianças". No entanto, o site "Literatura Infantil" não disponibiliza recursos em multimídia para a educação infantil.

O site "Brincadeira de crianças", por outro lado, apresenta links para uma variedade de recursos. Porém, não enfoca nem a lingua- 
gem, nem a educação infantil. É necessário que o professor investigue que recursos seriam adequados a essa fase do desenvolvimento. Nesse sentido, na lista de links disponibilizados, encontramos um link para um site de jogos educativos (Escola Games) que inclui recursos para a leitura em multimídia e recursos para a alfabetização, como estes:

Figura 1 - Um dia na fazenda

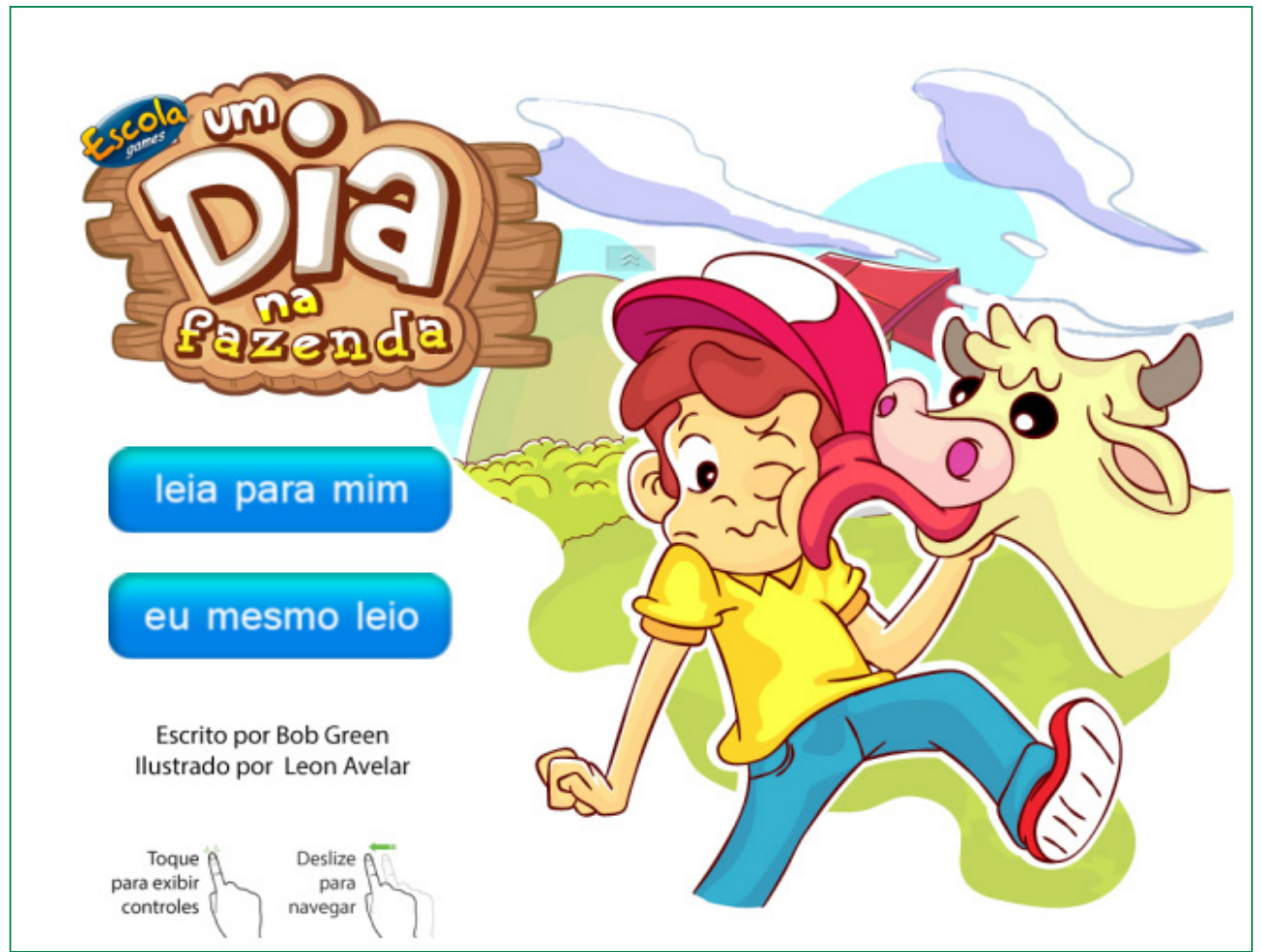

Fonte: <http://www.escolagames.com.br/livros/umDiaNaFazenda/>.
Os livros infantis do site contêm áudio (música e opção de narração), imagem, movimento e interação. O objetivo dos livros é, segundo o site, estimular a leitura e a criatividade. Como podemos observar, são recursos que podem ser utilizados na educação infantil.

Há, ainda, o "lguinho", que contém animações com historinhas para crianças pequenas:

Figura 2 - Adaptação de Os Três Porquinhos

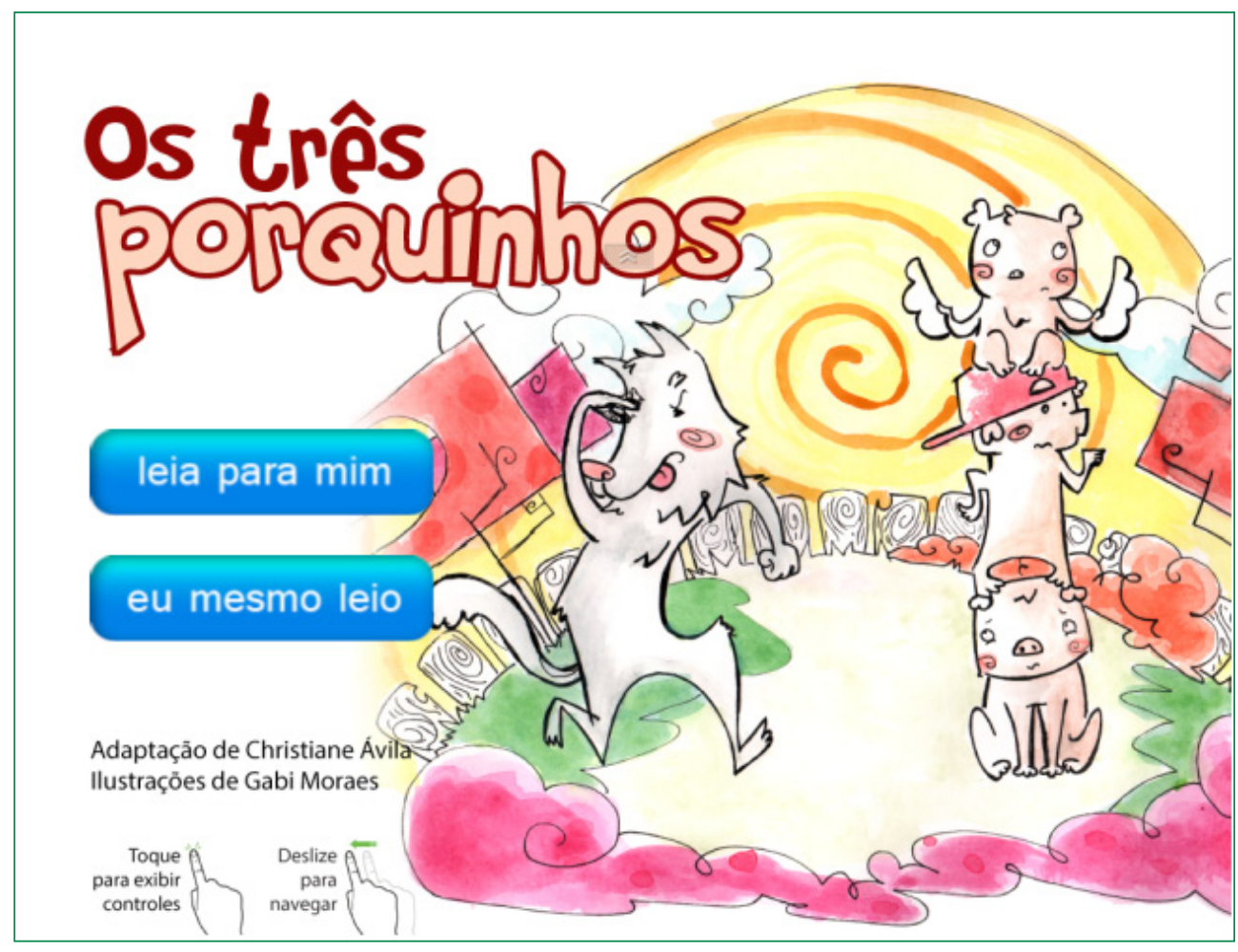

Fonte: <http://www.escolagames.com.br/livros/osTresPorquinhos/>. 
Figura 3 - Historinha animada

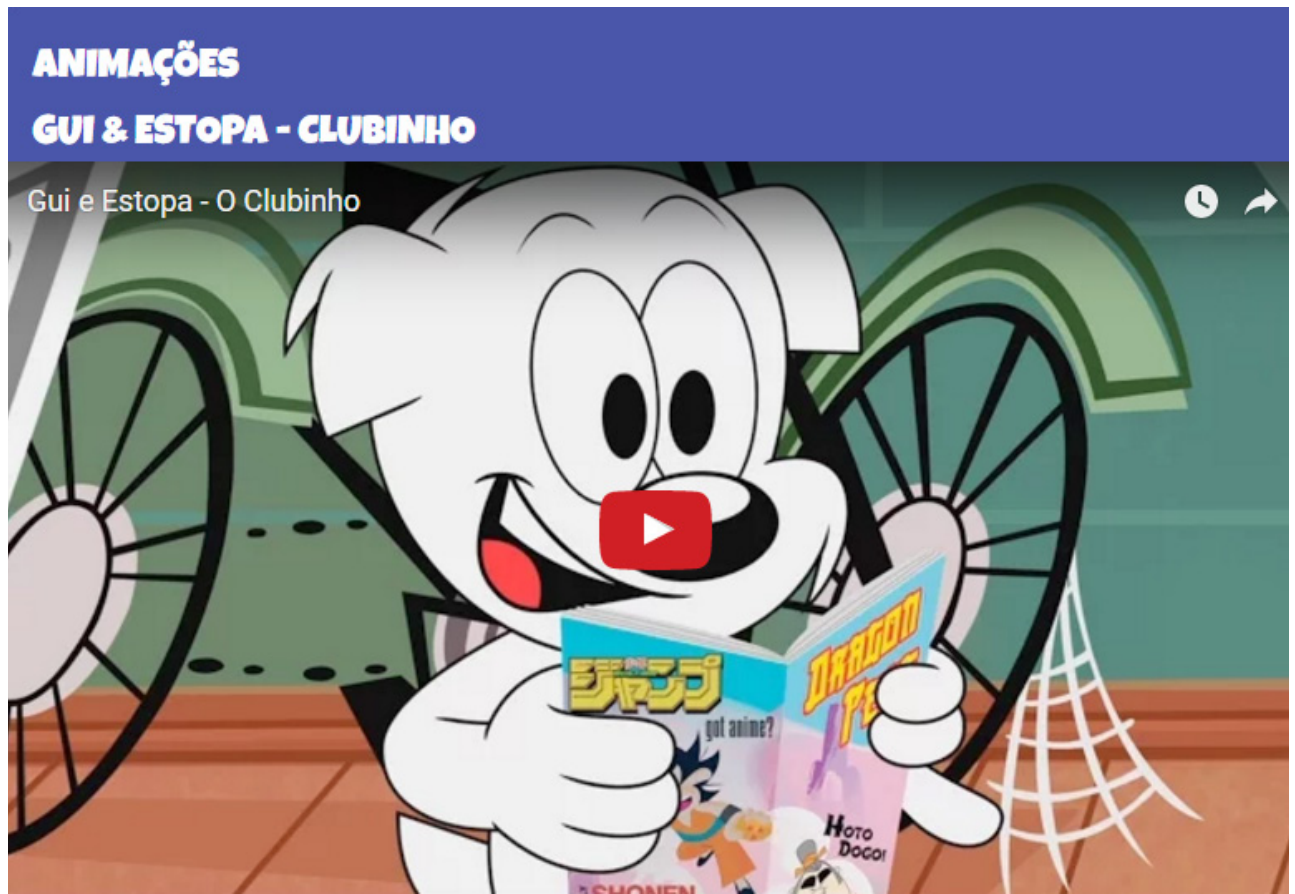

Fonte: <http://iguinho.com.br/gui-estopa-clubinho.html>.

Como podemos observar, essas ferramentas proporcionam o desenvolvimento de habilidades adequadas à fase do desenvolvimento infantil. Elas estimulam o interesse por histórias, pela criatividade e pela imaginação, explorando a percepção acústica, visual, além da compreensão de narrativas. Favorece, ainda, um preparo para a pedagogia do multiletramento. Lamentavelmente, porém, não oferecem softwares educacionais para a interação e a colaboração em leitura, nem para atividades, a partir da leitura.

\section{Considerações finais}

Como podemos observar, o Portal do Professor está distante do objetivo a que se propôs, isto é, o de apoiar os processos de formação dos professores brasileiros e enriquecer a sua prática pedagógica. Os poucos recursos educacionais oferecidos são limitados, não condizentes nem mesmo com a realidade de exposição a mídias (como a televisão) a que as crianças estão acostumadas. Os recursos educacionais mais variados encontravam-se em um site temático, cujo link estava disponibilizado no Portal, e não no próprio Portal. Afora isso, esse site temático não possui o filtro para que o professor possa fazer uma pesquisa voltada à educação infantil.

Um comentário adicional se faz necessário. Merece destaque a presença de recursos educacionais traduzidos de outros idiomas, que não foram selecionados para os propósitos desta pesquisa. Esses recursos eram mais elaborados, apresentando mais riqueza em termos de uso de multimídia, à semelhança do que ocorre no mercado editorial no Brasil, para essa fase do desenvolvimento, cujos livros apresentam recursos variados de estimulação da criança.

Ressaltamos, também, que a baixa disponibilidade de recursos contrasta com o número de acessos aos recursos. Isso revela o interesse de profissionais por recursos educacionais que ofereçam suporte às práticas de incentivo à leitura na educação infantil.

Ademais, gostaríamos de reiterar o fato de que não advogamos o uso de recursos em multimídia em detrimento dos livros infantis. Pelo contrário, acreditamos que a leitura do livro para a criança tem suas vantagens, principalmente pela interação com os educadores e uma possibilidade maior de contato e afeto. Por isso, causou-nos estranheza a disponibilização massiva do recurso de áudio, para narrar histórias que poderiam ser lidas por um adulto em contato direto com a criança. 
A esse respeito, embora acreditemos que a leitura de livros para essa fase do desenvolvimento seja essencial, o uso de recursos em multimídia permite a exploração de estímulos diferentes, a muitos dos quais a criança já está exposta, sem um trabalho pedagógico. Atualmente, existe uma necessidade de desenvolvimento de habilidades linguísticas e cognitivas mais próximas à cultura multiletrada, proporcionada, sobretudo, pelo desenvolvimento tecnológico. Softwares com leituras, brincadeiras e jogos interativos abrem possibilidades de leituras colaborativas, em que uma criança pode auxiliar a outra na compreensão de regras, o que caracterizam formas interessantes de leitura e de construção do pensamento lógico.

O Portal do Professor faz parte das políticas públicas para a educação. Entretanto, está muito distante de auxiliar os professores na promoção de uma educação infantil de qualidade, que é o objetivo do Marco Legal da Primeira Infância. Uma nova pesquisa, portanto, deverá ser realizada, quando da implementação do Marco, com vistas a verificar se foram apresentadas soluções para o problema aqui apresentado. Por enquanto, deixamos as plataformas "Escola Games" (www.escolagames.com.br) e "Iguinho" (www.iguinho.com.br) como as duas possibilidades interessantes para uso pedagógico na educação infantil.

\section{Referências}

ANDRADE, Susanne Anjos; SANTOS, Darci Neves; BASTOS, Ana Cecília, PEDROMÔNICO, Márcia Regina Marcondes; ALMEIDA-FILHO, Naomar; BARRETO, Mauricio. Ambiente familiar e desenvolvimento cognitivo infantil: uma abordagem epidemiológica. Revista Saúde Pública, v. 39, n. 4, 2005.

BELLONI, Maria Luiza. GOMES, Nilza. Infância, mídias e aprendizagem: autodidaxia e colaboração. Educação e Sociedade, v. 29, n. 104, 2008.

BRASIL. Parâmetros Curriculares Nacionais $1 \underline{1}$ a $a$ 4⿳a Séries. Disponível em: <http://portal. mec.gov.br/par/195-secretarias-112877938/seb-educacao-basica-2007048997/12640parametros-curriculares-nacionais-1o-a-4o-series>. Acesso em: mar. 2016.
BRASIL. Portal do professor. Disponível em: <http://portaldoprofessormec.gov.br/sobre. html>. Acesso em: abr. 2016.

BRASIL. INEP-PISA. O que é o Pisa. Disponível em: <http://portal.inep.gov.br/pisaprograma-internacional-de-avaliacao-de-alunos $>$. Acesso em: abr. 2016.

BRASIL. INEP-PROVINHA BRASIL. Apresentação. Disponível em: <http://provinhabrasil. inep.gov.br/>. Acesso em: abr. 2016.

BRASIL. INEP-SAEB. O que é o SAEB? Disponível em: <http://portal.inep.gov.br/web/ guest/saeb>. Acesso em: abr. 2016.

BRASIL. Marcolegalda primeirainfância. Disponível em:<http://marcolegalprimeirainfancia. com.br/>. Acesso em: mar. 2016

COELHO, Nelly Novaes. Literatura infantil: teoria, análise, didática. São Paulo: Moderna, 2000 .

COSENZA, Ramon M.; GUERRA, Leonor B. Neurociência e educação: como o cérebro aprende. Porto Alegre: Artmed, 2011.

HANEY, M.; HILL, J. Relationship between parent-teaching activities and emergent literacy in preschool children. Early Child Development and Care, v. 174, 2004.

MARTORELL, Gabriela. $O$ desenvolvimento da criança: do nascimento à adolescência. Tradução de Daniel Bueno e Régis Pizzato. Porto Alegre: AMGH, 2014.

SALLES, Jerusa Fumagalli; CORSO, Helena Vellinho; PICCOLO, Luciane Rosa; MINÁ, Camila Schorr. Normas de desempenho em compreensão de leitura textual para crianças de $1^{0}$ ano a $6^{\mathrm{a}}$ série. Psico, Porto Alegre, PUCRS, v. 46, n. 1, p. 68-78, jan.-mar. 2015.

SALLES, Jerusa Fumagalli; CORSO, Helena Vellinho. Relação entre leitura de palavras isoladas e compreensão de leitura textual em crianças. Letras de Hoje, Porto Alegre, v. 44, n. 3, p. 28-35, jul./set. 2009.

SCARPA, Ester Mirian: Aquisição da Linguagem. In.: MUSSALIM, Fernanda; BENTES, Anna Christina (Orgs.). Introdução à lingüística: domínios e fronteiras. São Paulo: Cortez, 2001. p. 203-232.

ROJO, Roxane; MOURA, Eduardo. Multiletramentos na escola. São Paulo: Parábola, 2012.

Recebido em 06/04/2016.

Aceito em 17/05/2016 